\title{
İmperfore himen olgu sunumu
}

\section{Imperfore hymen case report}

\author{
İsmail Yılmaz ${ }^{1}$ Melike Pündük Yılmaz² $\quad$ Cemile Özcan Uçar ${ }^{3}$ (D) \\ ${ }^{1}$ Düzce Atatürk Devlet Hastanesi, Kadın Hastalıkları ve Doğum Uzmanı, Düzce, Türkiye \\ ${ }^{2}$ Düzce İ Sağlık Müdürlüğü, Düzce, Türkiye \\ ${ }^{3}$ İstanbul Sultanbeyli Devlet Hastanesi, Kadın Hastalıkları ve Doğum Uzmanı, İstanbul, Türkiye
}

\section{Öz}

İmperfore himen genellikle adölesan dönemde ortaya çıkan Müllerian kanal anomalisidir. Ergenlik döneminde ağrı, hematokolpometra ve primer amenore ile kendini gösterir. Tedavi edilmeyen hastalarda endometriozis ve infertilite gibi ciddi komplikasyonlar gelişebilir. İmperfore himenin tedavi yöntemi himenektomi ya da himenotomidir. Olgumuz, 11 yaşında kız çocuğu, bakire, primer amenoreli olup karın ağrısı şikâyetiyle acil servisten başvurmuş, yapılan fizik muayene ve görüntüleme yöntemleri sonucundan imperfore himen tanısı almıştır. Cerrahi yöntem ile himene horizontal ve vertikal birer santimetrelik kesi yapılmıştır. Yaklaşık 400 cc eski kanamaya ait materyal aspire edilmiştir. Himen ağzı dört bölgeden 2.0 rapid vicryl ile dışarı ağızlaştırılmıştır. Sonuç olarak, karın ağrısı ile başvuran, primer amenoreli adölesanlarda altta yatan imperfore himen olasılığı göz önünde bulundurulmalıdır.

Anahtar Sözcükler: İmperfore himen, amenore, himenotomi, pelvik ağrı.

\section{ABSTRACT}

Imperforate hymen is a Mullerian duct anomaly that usually occurs in the adolescent period. Pain during adolescence is manifested by hematocolpometra and primary amenorrhea. Serious complications such as endometriosis and infertility may develop in untreated patients. The treatment method of imperforate hymen is hymenectomy or hymenotomy. Our case is an 11-year-old woman, virgin, with primary amenorrhea and admitted to the emergency department with the complaint of abdominal pain and was diagnosed with imperforate hymen as a result of physical examination and imaging methods. A horizontal and vertical one $\mathrm{cm}$ incision was made with the surgical method. Approximately $400 \mathrm{cc}$ of old bleeding material was aspirated. The hymen mouth was sutured from four regions with 2.0 rapid vicryl. Consequently, the possibility of underlying imperforate hymen should be considered in adolescents with primary amenorrhea presenting with abdominal pain.

Keywords: Imperforate hymen, amenorrhea, hymenotomy, pelvic pain.

\section{GiRiş}

İmperfore himen, konjenital vajinal çıkış tıkanıklığı olarak tanımlanır (1). Kadın üreme sisteminin en sık görülen obstrüktif konjenital anomalisidir ve insidansı 10.000 'de bir olarak görülmektedir (2).

Ağrı, hemoperitoneum, endometriozis, retrograd menstrüasyon ve infertilite gibi komplikasyonları önlemek için erken tanı ve uygun cerrahi yönetim gerekmektedir. Hastalar sıklıkla, alt karın ağrı ve/ veya pelvik ağrı, hematokolpometra, defekasyon yaparken ağrı ve üriner retansiyon gibi şikâyetler ile imperfore himen tanısı alırlar ve bu tanı translabial veya transperitonel ultrasonografi ile doğrulanabilir (3). 
İmperfore himen tanısı alan hastada, uterusta veya batında biriken kanı boşaltmak için basit bir yöntemle himene cerrahi insizyon uygulanır (4). Olguda 11 yaşındaki adolesan dönemdeki bir kız çocuğun 3 aylık siklik karın ağrısı ile imperfore himen tanısı raporlanmıştır. Hastanın ailesinden tıbbi verilerinin yayınlanabileceğine ilişkin yazılı onam belgesi alındı.

\section{OLGU}

Olgumuz karın ağrısı şikayeti ile acil servise başvuran 11 yaşındaki bir kız çocuğudur. Karın ağrısı şikayetinin 3 aydır siklik olarak devam ettiğini ifade etti. Primer amenoreik olan hasta, acilde yapılan muayene sonrası bilgisayarlı tomografi (BT) çekildi, sonucunda aksiyel kesitlerde 92×85 mm, sagital kesitlerde ise $80 \times 151 \mathrm{~mm}$ ebatlarında hematokolpos ve hematometra ile uyumlu görünüm izlendi. Hasta, acil servisten jinekoloji polikliniğine yönlendirildi. Primer amenoresi olan hastanın yapılan muayenesinde yaygın karın ağrısı, batında şişlik ve vajinal muayenede ıkınma ile himen seviyesinde büyük bir mavi şişkinlik gözlemlendi (Şekil-1a). Yapılan abdomen ultrasonda uterus altında vajina bölgesi hematokolpos ile uyumlu izlendi. Hastaya genel anestezi altında, steril boyama ve örtünmeyi takiben steril sonda uygulandı (ConvaTec, TR). İnspeksiyonda imperfore himen görüldü. Himene bisturi ile horizontal ve vertikal iki adet birer santimetrelik kesi yapıldı. Yaklaşık 400 cc eski menslere ait materyal aspire edildi. Himen ağzı dört bölgeden 2.0 rapid vycril ile dışarı ağızlaştırıldı (Vıcryl Rapıde,USA) (Şekil-1b). Drenajın devamı için vajinaya $20 \mathrm{cc}$ ile şişirilmiş sonda yerleştirildi (ConvaTec,TR). Kanama kontrolü yapıldı. Kanama kontrolü sonrası komplikasyon gelişmedi ve operasyona son verildi.

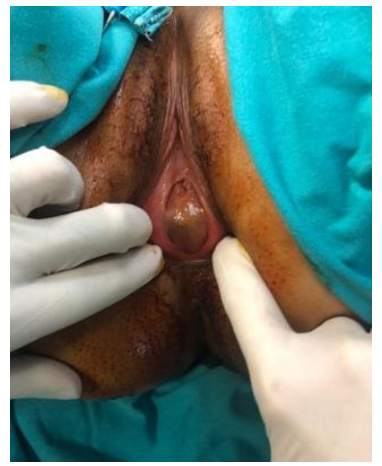
şişkin kapalı himen a. Mavimsi, yarı saydam ve

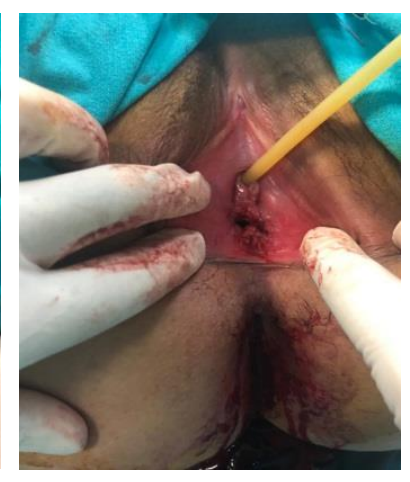

b. Himenotomi sonrası düzeltme
Şekil-1. Himenotomi. a. Mavimsi, yarı saydam ve şişkin kapalı himen, b. Himenotomi sonrası düzeltme.

\section{TARTIŞMA}

Adolesan dönemde siklik karın ağrısı şikayeti olan primer amenoreli olgularda imperfore himenden şüphelenmek gerekir. Bulguları hematokolposun büyüklüğü ve yaptığı basıya bağlı olarak defekasyonda ağrı, üriner retansiyon vb. şikayetlerle beraber siklik karın ağrısı gözlenmektedir. İmperfore himenin ortalama görülme yaşı 11-16'dır (5). Kliniğimize başvuran hastanın yaşı ise 11'di ve 3 aydır devam eden karın ağrısı şikayeti mevcuttu. Wong ve ark.'nin yaptığı çalışmada ise 14 yaşında sağlıklı bakire kız çocuğu karın ağrısına bağı 6 aylık kabızlık şikayeti ile başvurmuştur (6). Abraham'ın yaptığı çalışmada ise 12 yaşındaki bir kız çocuğu 1 haftalık karın ağrısı ve 3 gündür idrara çıkamama öyküsü ile acil servise başvurmuştur (7). Ancak pubertal dönem ya da intrauterin dönemde teşhis edilebilen vakalar da mevcuttur (5).

Olguda batın da ağrılı bir kitle, hematokolpos ve hematometra mevcuttu. BT sonucunda aksiyel kesitlerde $92 \times 85 \mathrm{~mm}$, sagital kesitlerde ise $80 \times 151 \mathrm{~mm}$ ebatlarında hematokolpos ve hematometra ile uyumlu bulgular gözlemlendi. Benzer şekilde, Sorrentino ve ark.'nın sunduğu laparoskopik destekli imperfore himen olgu sunumunda klinik muayenede batında ağrıı, yaklaşık 190 x81×106 mm ölçülerinde kitle, perineal incelemede hematokolpos ve hematometra ile uyumlu bulgular gözlemlenmiş (8). Doğan ve ark.'nın sunduğu olgu sunumunda ise, overler net olarak izlenmemekle birlikte abdominopelvik MRG'de uterus sola deviye, vajina-serviks bölgesinde $95 \times 100 \times 200 \mathrm{~cm}$ boyutlarında hematom tespit edilmiş (9).

İmperfore himeninin tedavi yöntemi genellikle himenektomi ya da himenotomidir. Himene, vajinal mukus veya kanın tamamen boşaltılması için 'artı' veya 'vertikal çizgi' şeklinde bir kesi oluşturulur. Aynı zamanda vajinal re-stenozu önlemeye dikkat edilmelidir. Bunun için operasyon sonrası vajinada iki hafta boyunca foley kateter bırakan çalışmalar mevcuttur (6). Sunduğumuz vakada, bisturi ile himene horizontal ve vertikal 2 adet 1'er cm'lik kesi yapıldı. Yaklaşık 400 cc eski kanamaya ait materyal aspire edildi. Himen ağzı dört bölgeden 2.0 rapid vicryl ile dışarı ağızlaştırıldı (Vıcryl Rapıde, USA) (Şekil-1b). Doğan ve ark.'nın sunduğu olguda ise genel anestezi altında parsiyel himenektomi yaparak yaklaşık $600 \mathrm{cc}$ koyu kıvamlı hematom ile uyumlu mayi aspire edilmiş ve himen kenarlarında hemostaz 
sağlanarak eversiyon uygulanmış (9). Wong ve ark.'nın yaptığı çalışmada benzer şekilde, kızık zarı seviyesindeki mavi bir şişkin membran olduğu fark edilmiş, olgunun rahatlaması için hymenotomi yapılmış. Kızlık zarı betadin ile temizlenerek, steril neşter yardımı ile $5 \mathrm{~mm}$ 'lik kesi oluşturulmuş büyük miktarda çikolata benzeri sıvı boşatılmış (6). Abraham'ın yaptığı çalışmada ise dış genital bölgede mavimsi, şişkin deliksiz kızlık zarı gözlemlenmiş, çapraz bir kesi ile 300 cc eski menarş kanıyla uyumlu çikolata renkli sıvı boşaltılmış ve 4-0 vicryl sütür ile kızlık zarı kenarlarının marsupiyalizasyonu yapılmıştır (7).

\section{SONUÇ}

Basit bir cerrahi müdahale ile tedavisi sağlanabilen ancak bekaretin göstergesi olarak bilinen kızlık zarının, bütünlüğünün korunması, hastanın gelecekteki sosyo-kültürel statüsü ve cinsel hayatı göz önüne alındığında minimal bir kesi ile tedavinin yapılması önem taşımaktadır.

\section{Çıkar çatışması}

Yazarlar arasında çıkar çatışması bulunmamaktadır.

\section{Kaynaklar}

1. Winderl LM, Silverman RK. Prenatal diagnosıs of congenital imperforate hymen. Obstetrics \& Gynecology. 1995; 85 (5): 857- 60.

2. Heger AH, Ticson L, Guerra L, et al. Appearance of the genitalia in girls selected for nonabuse: review of hymenal morphology and nonspecific findings. J Pediatr Adolesc Gynecol. 2002; 15 (1): 27-35.

3. Coppola L. Unique case of imperforate hymen. North American Society for Pediatric and Adolescent Gynecology. 2015: 1-3.

4. Ossman AME, EI- Masry YI, EI- Namoury MM, Sarsik SM. Spontaneous reformation of imperforate hymen after repeated hymenectomy. Journal of Pediatric and Adolescent Gynecology. 2016; 29 (5): 63- 5.

5. Tekin YB, Güven ESG, Şahin FK. Imperfore hymen sekonder oluşan pelvik kitlenin hymen kouyucu cerrahi ile tedavisi. Ege Tıp Dergisi. 2016; 55 (1): 29-31.

6. Wong, J.W.H., Siarezi, S. (2019). The Dangers of hymenotomy for imperforate hymen: A case of latrogenic pelvic inflammatory disease with pyosalpinx. Journal of Pediatric and Adolescent Gynecology. 432-435. https://doi.org/10.1016/j.jpag.2019.04.002.

7. Abraham, C. (2019). Imperforate hymen causing hematocolpos and urınary retention. The Journal of Emergency Medicine, 1-3. https://doi.org/10.1016/j.jemermed.2019.03.014.

8. Sorrentino F, Angioni S, Pontis A, Greco F, Scutiero G, Nappi L. Laparoscopically assisted treatment of imperforate hymen in a patient with ventriculo- peritoneal (VP) shunt for congenital hydrocephalous: A case report. International Journal of Surgery Open. 2018: 66- 8.

9. Doğan ÖF, Şentürk M, Aslan S, Öge T, Aydın Y. Abdominal kitle ile başvuran imperfore himen olgusu. Osmangazi Tıp Dergisi. 2014; 36 (3): 1-4. 